\title{
Ação Comunicativa: um olhar sobre processos de gestão de uma Rede de Atenção Psicossocial
}

\author{
Communicative Action: an overview of the management processes \\ of a Psychosocial Care Network
}

Maria Carolina Pinheiro Meirelles (https://orcid.org/0000-0003-1567-2347) ${ }^{1}$

Luciane Prado Kantorski (https://orcid.org/0000-0001-9726-3162) ${ }^{2}$

${ }^{1} 3^{\text {a }}$ Coordenadoria Regional de Saúde, Secretaria da Saúde do Rio Grande do Sul. Av. Borges de Medeiros 1501, $6^{\circ}$ andar, Praia de Belas. 90119-900 Porto Alegre RS Brasil. carolinapmeirelles@ yahoo.com.br

${ }^{2}$ Faculdade de Enfermagem, Universidade Federal de Pelotas. Pelotas RS Brasil.

\begin{abstract}
This paper is a qualitative evaluation of the main results of an evaluation study on management processes of a Psychosocial Care Network, in the light of the Theory of Communicative Action. The data collection included 19 individual semi-structured interviews with participants of the Management Collegiate and 20 hours of participant observation in eight meetings of this collegiate, from May to September 2015, with analysis using a hermeneutic-dialectic approach. The results showed a complex network of psychosocial care with management processes related to instrumental and communicative actions. Instrumental action was demonstrated in discussions about the rigid use of workflows, rules and protocols; prescriptive actions without collective negotiation and without user inclusion; and medicalization based on technical criteria alone. The communicative action was to be seen in actions of agreement on workflows, discussions and case referrals; intersectoral agreements with the judiciary; and deliberations of the Management Collegiate on cases, which are not solved only with a technical approach. The conclusion drawn is that the management processes of a Psychosocial Care Network are guided by communicative action, but also require overcoming an action defined by instrumental actions alone.
\end{abstract}

Key words Health management, Mental health, Qualitative research, Health evaluation
Resumo Trata-se de uma avaliação qualitativa, com os principais resultados de um estudo de avaliação sobre processos de gestão de uma Rede de Atenção Psicossocial à luz da Teoria da Ação Comunicativa. A coleta de dados incluiu 19 entrevistas individuais semiestruturadas com participantes do Colegiado Gestor e 20 horas de observação participante em oito reuniões deste colegiado, de maio a setembro de 2015, com análise de abordagem hermenêutica-dialética. Os resultados apontaram uma complexa rede de atenção psicossocial com processos de gestão relacionados com o agir instrumental e com o agir comunicativo. O agir instrumental foi demonstrado em discussões sobre a utilização rígida de fluxos, normas e protocolos; ações prescritivas sem negociação coletiva e sem inclusão do usuário; e medicalização baseada apenas em critérios técnicos. $O$ agir comunicativo evidenciou-se em ações de pactuação de fluxos, discussões e encaminhamento de casos; pactuações intersetoriais com o judiciário; e deliberações do Colegiado Gestor sobre casos, que não se resolvem apenas com o tecnicismo. Conclui-se que processos de gestão de uma Rede de Atenção Psicossocial são orientados por um agir comunicativo, mas ainda requerem a superação de um agir capturado somente por ações instrumentais.

Palavras-chave Gestão em saúde, Saúde mental, Pesquisa qualitativa, Avaliação em saúde 


\section{Introdução}

Diante de um cenário de fragilidades das politicas públicas em saúde no Brasil, que incluem a reformulação da Política Nacional de Saúde Mental, tendo-se por base a Portaria $3.588 / 2017^{1}$, que reconstitui a "rede de saúde mental", numa perspectiva reducionista de rede como conjunto de serviços de saúde, com ênfase em serviços especializados e o reconhecimento dos hospitais psiquiátricos como parte da mesma, urge reafirmar o potencial dos processos de gestão de redes de saúde em defesa da Reforma Psiquiátrica Brasileira.

A Organização Mundial da Saúde ${ }^{2}$ destaca a necessidade de pesquisas, acompanhamento e avaliação em saúde mental para o embasamento das políticas nacionais de saúde mental, de modo que a Reforma Psiquiátrica no Brasil, como parte de um processo aberto e em construção, também tem a avaliação de serviços públicos e suas conexões com a rede de cuidado em saúde como fundamental para o desenvolvimento do sistema de saúde e de seu controle pela sociedade ${ }^{3}$.

No contexto de reorientação do SUS pelo Decreto $7.508^{4}$, com a definição de Redes de Atenção à Saúde (RAS) e Portas de Entrada, incluindo a Atenção Psicossocial, a Política Nacional de Saúde Mental apresentou avanços com a Portaria 3.088/2011 ${ }^{5}$ ao instituir a Rede de Atenção Psicossocial (RAPS). Uma rede constituída por diversos pontos de atenção, desde a atenção básica até a reabilitação psicossocial, a ser coordenada por Grupos Condutores Municipais (GCM)

O conceito de RAS tem adquirido relevância no fortalecimento do SUS, e perpassa vários campos do conhecimento, contudo todos convergem no entendimento de que não se trata apenas da articulação de serviços com características semelhantes ${ }^{6}$. Faz-se necessário compreender as redes de saúde na perspectiva de fortalecimento das conexões e dos modos de comunicação entre os serviços ou pontos de atenção que, necessariamente, ocorrem através das relações estabelecidas entre os diversos atores, considerando-se fundamental o papel dos processos de gestão para a construção e o funcionamento de redes "quentes e produtoras de vida".

A integração entre serviços de saúde depende do estabelecimento de processos comunicativos de gestão ${ }^{7}$. Além das normatizações, em especial na construção e ativação de processos de gestão de redes de atenção psicossocial, são necessários modos de agir que potencializem a capacidade de tomada de decisões, através de uma racionalidade comunicativa.
Os processos de gestão podem ser mediados por instâncias colegiadas, mas dependem das formas de comunicação e implicação dos atores sociais envolvidos, na construção de ações coletivas por um bem comum, e dialogam com Teoria da Ação Comunicativa (TAC) quando propõem o recurso do entendimento mútuo como meio para obter consensos. Neste sentido, buscou-se na TAC a possibilidade de uma ferramenta para explorar estes processos de gestão, considerando o uso comunicativo cotidiano da linguagem por sujeitos que interagem, num processo de práxis social $^{8,9}$.

Para Habermas ${ }^{9,10}$ a Teoria da Ação comunicativa divide a sociedade em duas esferas coexistentes: a do Mundo da vida, de um agir comum, que diz respeito a reprodução simbólica, de linguagens e redes de significados (visão de mundo), que é permeada pela Razão Comunicativa/ Ação Comunicativa, na qual coexiste a comunicação livre, racional e crítica orientada para o entendimento mútuo, tida como uma Racionalidade Comunicativa; e a esfera do Sistema, como a da reprodução material e da lógica instrumental (adequação dos meios aos fins), das relações hierárquicas (poder político) e de intercâmbio (economia). Esta é permeada pela Razão Instrumental/Ação Instrumental, e busca alcance dos objetivos de qualquer modo (os fins justificam os meios) e, mesmo em cooperação, cada indivíduo só se interessa com o que pode ganhar, determinando uma Racionalidade Técnica.

Há uma correlação direta entre ação comunicativa que reproduz as estruturas simbólicas do mundo da vida (cultura, sociedade, pessoa). Para o entendimento mútuo, a ação comunicativa permite transmitir e renovar o saber cultural; como meio de coordenação da ação, ela propicia a integração social; e para socialização, serve à formação da personalidade individual ${ }^{11}$.

A Ação Comunicativa baseia-se em princípios éticos que garantem a participação dos atores sociais nas decisões através de discussões ou falas, avaliando as demandas do mundo da vida, e buscando equilibrar os interesses e as propostas de ações. Os conflitos não se resolvem por simples solução, mas pela solução mais adequada, e consensualizada pelos participantes.

Habermas ${ }^{12}$ chamou a atenção para a importância do papel da esfera pública na mediação entre a sociedade civil e a sociedade política. A interação comunicativa é o grande mecanismo coordenador da sociedade civil cujo traço característico, a autonomia de comunicação, é responsável pelo seu potencial crítico ${ }^{12}$. 
A gestão de redes implica trabalhar rotineiramente na produção de consensos e decisões político-administrativos, negociar as soluções e monitorar e avaliar, permanentemente, os processos $^{13}$, e embora existam avanços com normatizações e instrumentos de gestão em saúde, como leis, portaria, planos, relatórios e ações reguladoras, ações de monitoramento e avaliação, ainda precisam ser incorporadas nos processos de trabalho cotidianos da gestão.

Deste modo, no presente artigo apresentamse os principais resultados do estudo que objetivou avaliar processos de gestão de uma Rede de Atenção Psicossocial à luz da Teoria da Ação Comunicativa.

\section{Métodos}

Trata-se de um recorte da pesquisa intitulada "Avaliação dos processos de gestão de uma Rede de Atenção Psicossocial à Luz da Teoria da Ação Comunicativa" aprovada pelo CEP-FM/UFPel. Estudo qualitativo desenvolvido num município da região sul do estado do Rio Grande do Sul.

A coleta de dados foi realizada de maio a setembro de 2015 através de entrevistas individuais semi-estruturadas com 19 participantes do Colegiado Gestor da RAPS local e 20 horas de observação participante em oito reuniões deste colegiado.

Os 19 entrevistados são parte do total de 44 participantes diferentes entre as oito reuniões do Colegiado Gestor/Grupo Condutor Local, observadas, e tendo participado de pelo menos uma destas reuniões. Todos os participantes foram convidados a fazerem parte da pesquisa, contudo, nem todos foram entrevistados, em função da disponibilidade de tempo e interesses manifestados. As 19 entrevistas somaram um total de cerca de 10 horas, em média com 30 minutos cada.

A análise dos dados foi realizada considerando o referencial teórico da TAC, através das categorias de análise: o agir instrumental e o agir comunicativo. Utilizou-se como referencial metodológico uma abordagem hermenêutico-dialética buscando apreender a prática social empírica dos indivíduos em sociedade, em seu movimento contraditório $^{14}$.

Considerando princípios éticos da pesquisa em saúde, os participantes da pesquisa foram identificados como trabalhadores (profissionais dos pontos de atenção da RAPS), gestores (coordenadores dos pontos de atenção da RAPS, secretário(a) municipal de saúde, gestores de outros setores, e da região de saúde) e outros (residentes do curso de saúde mental coletiva ou trabalhadores de outros setores, como educação, por exemplo). Deste modo, as citações do material empírico estão identificadas nas falas das entrevistas com gestores e trabalhadores, como por exemplo: EG1 (Entrevistado(a) Gestor 01) ou ET3 (Entrevistado(a) Trabalhador 03). Os relatos das falas durante as observações como $\mathrm{O} 1$ (Observação 01), O2 (Observação 02), sucessivamente. As falas dos participantes das reuniões relatadas nas observações foram identificadas do mesmo modo quando se tratavam dos 19 entrevistados, e como P12O (Participante 12 Outros) ou P25G (Participante 25 Gestor) quando se trata apenas de um dos 44 participantes da reunião, mas que não foi entrevistado.

Os resultados da tese $\mathrm{e}^{15}$ apontaram a avaliação de uma complexa rede de atenção psicossocial, com vários pontos de atenção e equipes multiprofissionais de diversas formações. Identificaram-se ações de planejamento e avaliação em saúde, produção de cuidado em rede, promovendo integração, articulação da rede, e compartilhamento do cuidado, como apoio matricial e ações de Educação Permanente em Saúde. Contudo, na tessitura deste artigo apresentam-se os resultados e discussões referentes às categorias analíticas e as ações compreendidas como representativas do Agir Instrumental e do Agir Comunicativo.

\section{Resultados e discussão}

Na Rede de Atenção Psicossocial avaliada, os processos de gestão são permeados por ações que envolvem diferentes modos e espaços de comunicação, desde o uso do telefone, ou modos presenciais através de visitas a outros pontos de atenção, reuniões de equipe e, principalmente, no Colegiado Gestor/Grupo Condutor Local. Modos de comunicação que, de acordo com a Teoria da Ação Comunicativa ${ }^{16}$, são baseados em atos de fala ${ }^{17,18}$.

A realização de atos de fala tem relação com pretensões de validade, citadas por um sujeito em comunicação com outros, podendo afirmar, declarar ou fazer uma promessa e se comprometer com a validez do que foi dito ${ }^{19,20}$.

Considerando-se a própria interpretação da Teoria da Ação Comunicativa percebe-se que não é simples, nem tão exato, identificar e ou diferenciar as ações instrumentais e as ações comunicativas porque, de qualquer modo, o Mundo da vida e o Sistema coexistem, e, muitas vezes, as 
ações estão permeadas pelos diferentes modos de agir propostos por Habermas ${ }^{9}$. Porém, ao lançar um cuidadoso olhar interpretativo sobre o tema, é possível identificar maiores ou menores aproximações com cada tipo de ação, apresentando ao leitor o que essencialmente distingue uma de outra.

Compreende-se que o que faz uma ação ser instrumental é sua intencionalidade e as condições sociais nas quais se baseia e opera, com um fim em si mesmo, apenas como modo de alcançar um objetivo a qualquer custo, de modo que os fins justifiquem os meios, afastando a racionalidade comunicativa da ação'.

Logo, é possível que o agir comunicativo também tenha em si a presença da norma, do institucionalizado pelo sistema, mas não se aprisiona e não se limita ao reconhecer o que não está posto, o que não está dado; percebe outros modos de racionalidade que considera as relações, o imprevisível do mundo da vida que exigem recriar, reinventar, com novos modos de se comunicar e agir, com base no entendimento mútuo entre os sujeitos da ação.

\section{Agir Instrumental}

Em geral, as ações produzidas no trabalho e na gestão em saúde são pautadas por ações do Sistema, com predomínio de uma racionalidade técnica, com hegemonia das práticas de saúde baseadas no modelo biomédico, ainda que a saúde mental venha buscando se afastar dessas práticas e desenvolvendo uma produção de cuidado interdisciplinar, territorial e o mais próximo possível do mundo da vida.

Reconhecer ações como instrumentais não se resume a reconhecer o uso de normas, protocolos ou outras ferramentas já institucionalizadas pelo próprio sistema de saúde, mas de reconhecer os riscos ou prejuízos que ocorrem quando essas ações se sobrepõem à capacidade de reinventar, recriar, manter o protagonismo exigido pelo mundo da vida, e reduzem os processos de gestão e de cuidado a ações prescritivas, sem flexibilidade e limitadas na capacidade de produzirem relações suficientes para sustentar as conexões entre os pontos de atenção. Ou seja, são ações capturadas pelo domínio do sistema, sem reflexão ou crítica deste fazer, constituindo-se, assim, em ações instrumentais:

[...] lá dizia, que o CAPS seria o ordenador dessa rede. E aí eu fiquei pensando, nossa, como a gente hoje percebe isso de uma maneira diferente, porque o CAPS para nós aqui, ele é sim o ordenador de uma demanda que é dele. Se tiver alguém que está necessitando de uma internação, quem tem que regular esta internação, é o CAPS. Porque antes de ir para o hospital a pessoa precisa necessariamente ir ao CAPS. Isso a rede estabeleceu como um fluxo nosso, a não ser que seja um caso, de urgência ou emergência, que a gente vai chamar o SAMU que vai fazer esse atendimento. (E1G).

[...] fluxos, acho que são importantes, mas a gente tem que ter clareza. Eu acho que a gente enquanto rede tem que discutir fluxos e pactuar coisas, mas eu tenho certa dificuldade com os fluxos, porque às vezes paralisam. É fácil burocratizar as coisas, justificada pelos fluxos, e isso pode não ser bom. (E2G).

As falas demonstram que a organização e a pactuação de fluxos entre os pontos de atenção podem ser tanto uma ação instrumental quando segue normatizações sobre o papel desses serviços na rede, sem criticidade, sem apropriação e implicação dos sujeitos envolvidos no cumprimento da norma, quanto podem se constituir em uma ação comunicativa quando construídas a partir de pactuações locais e flexíveis para atender situações não contempladas na norma.

Outro exemplo de ação instrumental, que se restringe ao cumprimento da norma, não tendo significado para quem a utiliza, e por isso acaba nem sendo cumprida, é observado em relação ao uso de documentos de referência e contrarreferência, que costumam ser pouco utilizados; e quando o são, têm apenas o sentido de alcançar o objetivo de encaminhamento do usuário para ser atendido em outro ponto de atenção:

Então estamos agora, organizando isso, que é aquela "partezinha" debaixo do documento do sistema de referência, que é a contrarreferência, ela está ali só por estar, porque quase ninguém usa. Então a gente está vendo como que vai utilizar isso. (E1G).

A fala de E1G pressupõe esforços em buscar um entendimento coletivo para dar outro significado a essa ação de referência e contrarreferência como uma ação que qualifique o compartilhamento do cuidado e a interação entre as equipes, através de modos de comunicação para além da formalidade dos documentos.

Também se identifica como ações instrumentais aquelas indesejadas ações prescritivas e contraditórias ao trabalho em rede, que são ações que não resultaram de um entendimento mútuo entre a equipe e o usuário, e entre equipes que compartilham este cuidado:

Acontece do hospital às vezes, pós-alta, fazer encaminhamento e sugestão. [...] mas é mais do 
que sugestão, é pura indicação, de uma coisa, que é um projeto terapêutico que tem que ser construído com a equipe e com o usuário no CAPS, e não uma coisa prescritiva vinda de uma instituição para outra. (E2G).

Observa-se ações instrumentais que fazem parte dos processos de gestão que ao serem questionados podem ser repensados, não apenas para simples mudança, mas para não cristalizarem determinadas práticas que, em algum momento, podem exigir a quebra da norma ou do protocolo e exigir uma ação comunicativa, sem desconstituir ou desvalorizar a importância destes:

E2G: pergunta sobre como se dá o processo de internação dos usuários encaminhados pelo CAPS para Santa Casa, questionando por que eles têm que passar primeiro pelo pronto atendimento (PA). P5T: explicou o quanto é importante o usuário passar pela avaliação clínica do PA, e que esta corresponsabilização da equipe do PA com a da unidade de saúde mental foi construída há bastante tempo. Que é importante fortalecer a responsabilidade da equipe do PA em atender os usuários da saúde mental. P25G: diz que nos outros hospitais gerais da região, usuários que acessam diretamente o PA ou que são encaminhados pelos CAPS ou pela regulação regional/estadual, também dão entrada pelo PA, e que há necessidade de atentar para situações singulares que requerem maior diálogo entre as equipes: a que encaminhou, a que atende no $P A$ e a que receberá na unidade, para produção de cuidados que estão para além dos protocolos e normas. (O2).

A observação acima trata de uma norma do sistema, mas que talvez não seja decorrente de discussão e entendimento mútuo, por ainda gerar dúvidas sobre a sua necessidade. A resposta e os comentários proferidos procuram esclarecer e justificar a norma e a necessidade de reavaliar e até mesmo repactuar o estabelecido, de modo que situações singulares não tenham a produção do cuidado comprometida apenas em função do cumprimento de protocolos. Tal discussão reflete o emergir de questões que escapam ao sistema e que requerem o Agir Comunicativo.

Nas falas relatadas na observação a seguir, de uma reunião do colegiado com a presença do judiciário, ao tratarem da medicalização como uma ação prescritiva do setor de saúde e muitas vezes reforçada pelo setor judiciário, também demonstra diferentes visões, entendimentos e ações sobre uma mesma questão, que podem simplesmente ser guiadas pelas normas.

E9T: Fala que a sobrecarga de trabalho é comum a todos os setores. Fala da importância da conversa com outros serviços. E fala sobre as práticas manicomiais que também ainda acontecem nos serviços de saúde, como o excesso de medicalização de crianças, desde os primeiros sintomas, na escola. E fala da importância do Colegiado também conversar sobre medicalização. P12O: diz que os juízes só tomam decisões baseadas em avaliação técnica e que eles têm clareza que as compulsórias dificultam, mas que sobre as medicações, alguém prescreve aquilo. Eque muitos profissionais têm prescrito outras apresentações que não seguem os protocolos do SUS, e que fica difícil para o judiciário ter que verificar e comparar com os protocolos. Fala que uma parcela imensa do trabalho do judiciário está sendo acompanhamento da saúde. Fala dos laudos que são muito ruins e com pouca informação. E7T: A gente tem limites, por isso a rede é importante. P12O: diz que, se chegou a nós (judiciário) é porque a rede falhou em algum ponto. (O3).

As falas parecem explicitar as contradições presentes nos processos de produção do cuidado e da gestão, principalmente quando envolvem ações intersetoriais, atravessadas pelos diferentes entendimentos dos sujeitos envolvidos, fazendo emergir contradições entre o que entendem por necessidade ou o melhor cuidado a ser ofertado e o cumprimento das normas estabelecidas pelo sistema, preponderando o domínio de ações instrumentais.

Na situação do uso de medicamentos, tal ação é preocupante, pois conforme já mencionado é considerada uma ação social de grande impacto no mundo da vida. E, no caso de crianças, produz um comportamento "desviante" e produtor de novas necessidades e demandas ao setor de saúde que não podem ser resolvidas apenas com uma racionalidade técnica e instrumental.

Essas ações apontadas como ações instrumentais, ainda que com esforços na busca por um agir comunicativo, representam o pensamento Habermasiano ${ }^{10}$ que entende que os sujeitos podem a qualquer momento adotar um enfoque instrumental objetivando contextos normativos e abandonar a orientação mediante consenso, mas que nas sociedades modernas surgiram modos de organização e de relações sociais que não permitem mais atitudes regidas exclusivamente por modos normativos.

Neste caso, identifica-se o Colegiado Gestor como um espaço de interação social capaz de mediar um possível domínio do agir instrumental sobre o agir comunicativo. Bem como, conforme Gonçalves ${ }^{21}$ observa-se que os processos de gestão da RAPS avaliada não se constituem em ações que permaneçam exclusivamente sub- 
metidas a critérios técnicos de decisão racional, e que privilegiam o planejamento e o cálculo como partes integrantes de procedimentos que envolvem questões somente administrativas.

\section{Agir Comunicativo}

A ação comunicativa responde a ações demandadas pelo mundo da vida, por questões que escapam às normas e rotinas estabelecidas $\mathrm{e}$ às zonas de conforto dos trabalhadores e gestores, portanto, são vários os desafios para um agir produzido por diversos atores que buscam um entendimento mútuo.

Destacam-se as ações produzidas pelo Colegiado Gestor, dos seminários, reuniões de equipe, atividades de EPS, e outras, não havendo limites para uma ou outra dessas atividades dos processos de gestão que possibilitem o agir comunicativo, pois muitas ações envolvem mais de uma ou todas essas atividades:

Nós tínhamos sérios problemas com o sistema de referência e contrarreferência. Aos poucos através da comunicação feita no Colegiado, pactuando e repactuando, foi se vendo as possibilidades de melhorar essa comunicação. (E1G).

Talvez as ações que mais exijam o agir comunicativo sejam as ações de produção de cuidado em rede intersetorial, com o judiciário, a educação, a assistência social e a segurança pública, devido às diferentes concepções sobre os problemas de saúde.

Observa-se, nas deliberações do Colegiado Gestor, uma ação comunicativa em relação às questões sobre judicialização, como a criação de um Grupo de Trabalho (GT) para tratar do tema:

E2G: fala sobre marcar reunião do GT do Judiciário, e comenta que houve encaminhamento de pedido judicial de busca ativa de determinado usuário com pouca informação. E1G: diz que devem conversar com a juiza e orientou devolver o encaminhamento perguntando mais informações. Lembra que a composição do GT foi definida na reunião com a juiza, e que devem marcar uma data. [...] Esclarece que o GT é uma proposta da Secretaria de Saúde para pensar em estratégias de como lidarem com as questões que envolvem o judiciário e a rede de saúde mental. (O6).

P12O: Diz que já aconteceu o momento dela própria ter que decidir que a mãe fosse encaminhada a um serviço, e conta o caso em que na dúvida sobre qual era a situação real, ligou e conversou com trabalhadora do CAPSi, que disse que a criança estava bem, mas que a mãe é que tinha problemas. E4T: fala que outra família também era paciente do CAPSi e que haviam "tentado" encaminhar o pai e a mãe para o CAPSI e que também o serviço dizia que não era caso para CAPS. E1GI: Que este fato denunciou o ruído de comunicação entre os serviços. Que é preciso examinar o perfil de cuidado dos CAPS e reorganizar este cuidado na atenção básica. (O3).

Além dessas falas, destaca-se a pactuação realizada com o Ministério Público, sobre as demandas de internação compulsória serem encaminhadas para avaliação e regulação dos CAPS, como resultado de um consenso produzido com a gestão da RAPS e o Ministério Público.

Percebe-se a aproximação ou a necessidade do agir comunicativo nas questões intersetoriais, com ênfase na judicialização, pelo fato de que as situações demandadas extrapolam o sistema de saúde e envolvem outros setores, entre os quais a assistência social e o judiciário, com diferentes entendimentos sobre uma mesma questão. Logo, ainda que com leis, normas e tecnologias de cuidado disponíveis, é comum prevalecerem situações conflitantes que exigem uma racionalidade que não seja apenas objetiva ou subjetiva, e sim uma racionalidade comunicativa, como propõe Habermas?.

As questões citadas fogem ao possível de ser "resolvido" dentro dos saberes e fazeres de cada setor ou sistema, pois na tomada de decisão que envolve situações cotidianas e de sofrimento humano individual ou coletivo se constrói outro sistema que é intersubjetivo e abarcado pelo mundo da vida, requerendo um modo comunicativo relacional e capaz de produzir um entendimento que vise ao melhor encaminhamento para a questão pautada, sem a sobreposição e o domínio do poder de um setor sobre o outro.

Habermas compreende que a ciência e a técnica ampliam as possibilidades humanas, libertando o homem da dominação das necessidades materiais, mas se contrapõe a universalização da ciência e da técnica, e a penetração da racionalização científica e meramente instrumental em esferas de decisão, que necessitam de outro tipo de racionalidade: a racionalidade comunicati$\mathrm{va}^{9,21}$.

O Colegiado Gestor como uma ferramenta de gestão, é possivelmente capaz de promover um encontro intersetorial e intersubjetivo. É capaz de propiciar diferentes olhares e manifestações de cada participante sobre o outro, através das falas ou palavras proferidas, e mesmo que permeadas pela diversidade de saberes e fazeres técnicos muitas vezes dominados pelo tecnicismo e pelas relações de poder; podem desencade- 
ar ações pautadas na racionalidade comunicativa, exemplificadas pela formação de um GT para as questões judiciais e pelas pactuações entre os setores.

De acordo com Hardt e Negri ${ }^{22}$, o sujeito é entendido como alguém em relação com o outro, e que somos produto do olhar do outro forjando nossa subjetividade, que também é pensada na perspectiva da comunicação e da cooperação, na revelação com o outro e com as palavras.

Observou-se também que a tomada de decisão e a forma como foi coordenada a implantação do Apoio Matricial na RAPS avaliada, se configuram em produto de uma ação comunicativa, considerando-se que a questão sobre a necessidade de qualificar as ações de saúde mental na atenção básica foi levantada em discussões no Colegiado Gestor. Essas discussões geraram o planejamento e realização de um seminário para tratar dessa questão, no qual, a partir de discussões pautadas pelas experiências vividas e pelo entendimento mútuo dos participantes, se desdobrou em outra ação, a proposta de matriciamento para as UBS a ser realizada por profissionais dos CAPS que, junto ao NASF, passaram a cobrir toda a rede de atenção básica com o apoio matricial em saúde mental:

[...] o mais atual foi sobre a questão do apoio, como que ia se dar [...] a rede de saúde mental fez a proposta de ter os apoiadores dos serviços na atenção básica, então vai dois de cada CAPS [...] e conseguem estar presentes nas equipes de atenção básica, que era uma demanda de comunicação, para além do telefone, para além de só discutir algum caso pontual. [...] foi uma proposta que surgiu do seminário do início do ano, em que uma equipe de atenção básica que estava mais avançada em relação ao apoio apresentou sua experiência. [...] porque além do apoio matricial do NASF, tem esse profissional do CAPS que vai lá, como uma coisa que ainda está iniciando, mas que facilitou também esse processo de comunicação entre os serviços. Vai um do ad, um do infantil, um do CAPSI até uma equipe de atenção básica na reunião de equipe ou até mesmo conversando com alguém da equipe sobre a saúde mental. [...] eu acho que está tendo um certo efeito porque construiu uma proximidade entre as equipes e fica mais fácil de construir o cuidado compartilhado se as pessoas se encontram, se estão juntas. Isso a gente notou que rolou mais efeito do que outros processos que a gente vinha fazendo. (E18G).

Ainda que existam normatizações sobre matriciamento na legislação e nas referências sobre o tema, o modo como foi implantado e está sen- do desenvolvido é único, pois ocorre no mundo da vida, no cotidiano do trabalhado e das relações entre os atores envolvidos. $\mathrm{O}$ apoio matricial na essência se aproxima do agir comunicativo, pois se trata de uma tecnologia ou ferramenta de comunicação que busca a construção de projetos terapêuticos singulares a partir do entendimento mútuo de um coletivo de gestores, trabalhadores, usuários e comunidade, promovendo a articulação e a integração dos pontos de atenção nos níveis intra e intersetorial.

A sensação de ausência de profissionais, a mistura e confusão de modelos de cuidado e a primazia na utilização de tecnologias duras e ineficientes quanto à integralidade necessitam de investimento em tecnologias leves como centro do debate para a superação das mesmas, como o vínculo e articulação de rede na relação entre CAPS e $\mathrm{UBS}^{23}$.

A interlocução entre CAPS e ESF ocorre de forma diferente no território, com aproximações importantes e grandes desafios, mas com indicações de investir e acreditar na potencialidade da constituição de uma rede entre os CAPS e a atenção básica, a fim de garantir a integralidade aos usuários com transtorno mental ${ }^{24}$.

Em estudos ${ }^{25}$ sobre apoio matricial e redes de cuidado integral, apresentam conceitos, percepções e vivências trazidas pelos profissionais de Saúde Mental sobre seus cotidianos nos serviços de saúde, e demonstram que a integração desses serviços também promove um choque de encontros e o reconhecimento de realidades distintas com um intuito comum.

Essas considerações reafirmam a necessidade de pautar o apoio matricial na perspectiva do agir comunicativo, de maneira que não se transforme em mero agir instrumental para atender a demanda de especialistas na atenção básica.

Um sistema de gestão colegiada pode ser desenvolvido por meio de unidades de produção compostas por equipes de referência e equipes de apoio matricial, de acordo com as especificidades do processo de trabalho, em substituição aos recortes e limites dos núcleos profissionais ${ }^{26}$.

Assim, o Colegiado Gestor é um facilitador de ações comunicativas pela possibilidade de compartilhamento das decisões e responsabilidades e produção de novos fazeres a partir do entendimento entre os pares, observado especialmente nas discussões de casos:

Então, hoje o pessoal consegue abrir mais [...] traz para discutir no colegiado, participa, delibera junto e não é só trazer para alguém resolver. (E11G). 
[...] o espaço do colegiado da saúde mental é um espaço potente de constante avaliação dos processos, não tão formais, mais ali surgem nas pautas várias questões que são "objetos" de reflexão tanto para se "dar conta", como se resolver naquele momento da discussão. (E18G).

E1G: sobre o caso de um usuário X, questiona que alguém com frio e sem casa, não consegue se motivar para se tratar. E2G: diz que se é o caso ou não de estar com frio, mas que no momento é que dá para fazer e vamos adiante. Defende que precisa manter o contato com a assistência social, $e$ fazer o laudo. Falou da possibilidade da Assistente social do CAPSI, que foi do CAPS ad e que conhece o paciente, poder fazer o laudo. P14G: pergunta: ele está no ad? E6G: explica que ele fica uns dias, sai e volta, e agora acharam melhor que ele fique até resolver para não o fragilizar mais. P14G: diz que as pessoas o contratavam para bicos. E1G: reforça que a solução dele continuar no CAPS, é provisória. E6G: fala da busca de emprego para ele, que já distribuíram vários currículos. (O4).

E1G: Fala sobre o Usuário X que foi pauta de discussão em reuniões anteriores. Conta que ele está estudando, e que já foi feito o Laudo Social. P17T: também conta que retomaram contato com a irmã dele que mora em Pelotas, e com o desenvolvimento social, para resolverem a questão da habitação. (O5).

Os processos de gestão na saúde não garantem modelos condizentes com a complexidade do SUS, favorecendo a democratização das relações de trabalho e os processos de aprendizagem que o próprio trabalho pode produzir. Há necessidade de uma gestão participativa e colegiada capaz de ampliar a qualidade da gestão do trabalho, da educação, da atenção e do controle social ${ }^{27}$. Quando as discussões envolvem questões socioeconômicas e que extrapolam o sistema de saúde, os processos de gestão podem ser mais efetivos se buscarem um agir comunicativo, observados nas falas anteriores pelos proferimentos de afirmação, declarações e compromissos assumidos em reunião do Colegiado Gestor.

É importante destacar que, com o entendimento de redes como relações rizomáticas entre pessoas, e disparadoras de diferentes linhas e conexões, a partir dos modos de comunicação, muitas das questões requerem o contato entre os pontos de atenção e são pautadas pelo agir comunicativo:

P5T: traz a questão de que há umas três semanas estão com dificuldade de leitos, que as unidades de saúde mental estão lotadas, e que é preciso conversar mais, e equacionar a situação de pacientes que estão seguidamente internando [... ] e também comenta que têm ocorrido várias internações de crianças, o que leva a diminuir os leitos disponíveis. P25G: pergunta de que municípios são as crianças? P5T: diz que a maioria é do Município $X$ e dos abrigos. E2G: comenta que estão realizando reuniões com equipe do CAPSI e do Hospital para discutirem os casos. E6G: diz que o CAPSadIII também já tem agenda de reuniões com o Hospital para discutirem os casos comuns entre os dois serviços. (O7).

As falas da reunião acima expõem uma série de questões que não estão sendo suficientemente resolvidas ou encaminhadas por um agir instrumental e sim por compromissos assumidos através do reconhecimento de que são questões que requerem o entendimento e as proposições do coletivo.

\section{Considerações finais}

Entre os desafios dos processos de gestão numa complexa rede de saúde é relevante o permanente atravessamento das contradições entre o modelo manicomial e o da atenção psicossocial presente nas subjetividades e nas práticas dos sujeitos que produzem o cuidado, e que tem sido enfrentado nos processos de gestão local pelas oportunidades de encontros e trocas entre sujeitos que criticam o seu trabalho e o do outro, em potentes espaços de comunicação.

A gestão em saúde está permeada ou atravessada pelo sistema, pelas normas, mas se confronta e opera cotidianamente no mundo da vida, o que depende das ações comunicativas através dos atos de fala. São essas ações comunicativas que inventam e reinventam novas produções de cuidado em saúde, e dão o caráter protagonista da gestão local, que podem ser mais livres e mais criativas quando assumem diferentes configurações, em diferentes contextos, promovendo interação e articulação da rede, através do investimento nas relações e na mediação de conflitos, na busca pelo entendimento e pela produção de consensos.

Quando um ato de fala é capaz de ativar redes, no final há produção do cuidado a partir do protagonismo dos autores. Uma gestão pautada pela democracia é uma escolha política, no entanto, também é uma necessidade, de modo que processos de gestão que coordenam uma linha de cuidado, planejando, avaliando e produzindo cuidado através de ações comunicativas, se configuram em modos de emancipação, como capaci- 
dade de não se limitar, não depender do que está posto, do que já foi alcançado ou normatizado, enfim, capaz de produzir livremente.

Considera-se enfim, que os processos de gestão da RAPS avaliada são produtores de cuidado em rede, porque coordenam e promovem a integração de diversos pontos de atenção à medida que operam de modo participativo e democrático através de uma ação comunicativa linguisticamente mediada, buscando um poder criativo, protagonista e emancipatório dos sujeitos e da produção do trabalho em saúde.

De qualquer modo, a tese de que processos de gestão de uma Rede de Atenção Psicossocial são ações do Mundo da vida, orientados por um agir comunicativo, e ainda que pautados também pelo Sistema requerem a superação de um agir capturado por ações instrumentais, não se encerra nesta análise, e nem se configura na única das muitas e diversas questões que envolvem os processos de gestão de uma rede de atenção psicossocial. Certamente esta avaliação deixa margem para outros estudos, considerando-se os limites próprios do recorte do tempo, dos aspectos metodológicos e da possibilidade de, em um único estudo, abarcar o amplo contexto do objeto deste estudo.

\section{Colaboradores}

MCP Meirelles contribuiu com a concepção e o delineamento ou a análise e interpretação dos dados, redação do artigo ou a sua revisão crítica, e aprovação da versão a ser publicada. LP Kantorski contribuiu com a redação do artigo ou a sua revisão crítica, e aprovação da versão a ser publicada. 


\section{Referências}

1. Brasil. Portaria no 3.588, de 21 de dezembro de 2017. Altera as Portarias de Consolidação no 3 e no 6 , de 28 de setembro de 2017, para dispor sobre a Rede de Atenção Psicossocial, e dá outras providências. Diário Oficial da União 2017; 22 dez.

2. World Health Organization (WHO). Mental health action plan 2013-2020. Library Cataloguing-in-Publication Data. Geneva: WHO; 2013.

3. Queiroz MS, Delamuta LA. Saúde Mental e o trabalho interdisciplinar: a experiência do "Cândido Ferreira" em Campinas. Cien Saude Colet 2011; 16(8):36033612.

4. Brasil. Decreto no 7.508, de 28 de junho de 2011. Regulamenta a Lei no 8.080 , de 19 de setembro de 1990 , para dispor sobre a organização do Sistema Único de Saúde - SUS, o planejamento da saúde, a assistência à saúde e a articulação interfederativa, e dá outras providências. Diário Oficial da União 2011; 29 jun.

5. Brasil. Portaria no 3.088, de 23 de dezembro de 2011. Constitui a Rede de Atenção Psicossocial para pessoas com sofrimento ou transtorno mental e com necessidades decorrentes do uso de crack, álcool e outras drogas no âmbito do SUS. Diário Oficial da União 2011; 24 dez.

6. Righ L Redes de Saúde: uma reflexão sobre formas de gestão e o fortalecimento da atenção básica. In: Brasil. Ministério da Saúde (MS). Secretaria da Assistência à Saúde. Política Nacional de Humanização. Cadernos Humaniza SUS. Atenção Básica. Brasília: MS; 2010.

7. Schraiber LB. O Médico e suas Interações. A crise dos vínculos de confiança. São Paulo: Hucitec; 2008.

8. Habermas J. Teoría de la Acción Comunicativa. v. 1. Racionalidad de la acción y racionalización social. Mexico: Taurus; 2002.

9. Habermas J. Teoria do Agir Comunicativo: racionalidade da ação e racionalidade social. v. 1. São Paulo: Martins Fontes; 2012.

10. Habermas J. Teoria do Agir Comunicativo: sobre a crítica da razão funcionalista. v. 2. São Paulo: Martins Fontes; 2012.

11. Pinto JMR. A Teoria da Ação Comunicativa de Jürgen Habermas: Conceitos Básicos e possibilidades de aplicação à administração escolar. Paidéia 1995; (89):77-96.

12. Habermas J. Direito e Democracia: entre facticidade e validade. v. I. $8^{\mathrm{a}}$ ed. Rio de Janeiro: Tempo Brasileiro; 2003.

13. Mendes EV. As Redes de Atenção à Saúde. Brasília: OPAS; 2011.

14. Minayo MCS. O Desafio do Conhecimento: pesquisa qualitativa em saúde. 10a ed. São Paulo: Hucitec; 2007.
15. Meirelles MCP. Avaliação dos Processos de Gestão de uma Rede de Atenção Psicossocial à Luz da Teoria da Ação Comunicativa [tese]. Pelotas: Universidade Federal de Pelotas; 2016.

16. Habermas Y. Dialética e Hermenêutica. São Paulo: Editora L\&PM; 1987.

17. Austin J. How to do Things with Words. Oxford: Oxford University Press; 1962.

18. Searle JR. A Taxonomy of Illocutionary Acts in Language, Mind and Knowledge. Minneapolis: University of Minnesota Press; 1976.

19. Echeverria R. Ontologia del Lenguaje. Santiago: Dolmen; 1997.

20. Lima JC, Rivera FJU. Agir comunicativo, redes de conversação e coordenação em serviços de saúde: uma perspectiva teórico-metodológica. Interface (Botucatu) 2009; 13(31):329-342.

21. Gonçalves MA. Teoria da ação comunicativa de Habermas: Possibilidades de uma ação educativa de cunho interdisciplinar na escola. Educ Soc 1999; 20(66):125-140.

22. Hardt M, Negri A. Multidão: guerra e democracia na era do império. Rio de Janeiro: Record; 2005.

23. Araujo AK, Tanaka OY. Host Process Evaluation in Mental Health in the Midwest of São Paulo: the analysis of the relation between UBS and CAPS. Interface (Botucatu) 2012; 16(43):917-928.

24. Rodrigues ES, Moreira MIB. A Interlocução da Saúde Mental com Atenção Básica no Município de Vitória/ ES. Saude Soc 2012; 21(3):599-611.

25. Silva FP, Frazão IS, Linhares FMP. Práticas de saúde das equipes dos Consultórios de Rua. Cad Saude Publica 2014; 30(4):805-814.

26. Campos GWS. Um método para a análise e cogestão de coletivos. São Paulo: Hucitec; 2000.

27. Capra MLP. A Educação Permanente em Saúde como dispositivo de gestão setorial e de produção de trabalho vivo em saúde [tese]. Porto Alegre: Universidade Federal do Rio Grande do Sul; 2011.

Artigo apresentado em 03/01/2020

Aprovado em 11/07/2020

Versão final apresentada em 13/07/2020

Editores-chefes: Romeu Gomes, Antônio Augusto Moura da Silva 